\title{
A Study of Thin Film Resistors Prepared Using Ni-Cr-Si-Al-Ta High Entropy Alloy
}

\author{
Ruei-Cheng Lin,, Tai-Kuang Lee, ${ }^{2}$ Der-Ho Wu, ${ }^{1}$ and Ying-Chieh Lee ${ }^{3}$ \\ ${ }^{1}$ Department of Mechanical Engineering, National Pingtung University of Science \& Technology, Pingtung 91201, Taiwan \\ ${ }^{2}$ Department of Electrical Engineering, National Cheng Kung University, Tainan 701, Taiwan \\ ${ }^{3}$ Department of Materials Engineering, National Pingtung University of Science \& Technology, Pingtung 91201, Taiwan
}

Correspondence should be addressed to Ying-Chieh Lee; yclee@mail.npust.edu.tw

Received 23 October 2014; Revised 29 November 2014; Accepted 28 December 2014

Academic Editor: Ke Fu Yao

Copyright (C) 2015 Ruei-Cheng Lin et al. This is an open access article distributed under the Creative Commons Attribution License, which permits unrestricted use, distribution, and reproduction in any medium, provided the original work is properly cited.

\begin{abstract}
$\mathrm{Ni}-\mathrm{Cr}$-Si-Al-Ta resistive thin films were prepared on glass and $\mathrm{Al}_{2} \mathrm{O}_{3}$ substrates by $\mathrm{DC}$ magnetron cosputtering from targets of $\mathrm{Ni}_{0.35}-\mathrm{Cr}_{0.25}-\mathrm{Si}_{0.2}-\mathrm{Al}_{0.2}$ casting alloy and Ta metal. Electrical properties and microstructures of Ni-Cr-Si-Al-Ta films under different sputtering powers and annealing temperatures were investigated. The phase evolution, microstructure, and composition of NiCr-Si-Al-Ta films were characterized by X-ray diffraction (XRD), transmission electron microscopy (TEM), and Auger electron spectroscopy (AES). When the annealing temperature was set to $300^{\circ} \mathrm{C}$, the $\mathrm{Ni}$-Cr-Si-Al-Ta films with an amorphous structure were observed. When the annealing temperature was at $500^{\circ} \mathrm{C}$, the Ni-Cr-Si-Al-Ta films crystallized into $\mathrm{Al}_{0.9} \mathrm{Ni}_{4.22}, \mathrm{Cr}_{2} \mathrm{Ta}$, and $\mathrm{Ta}_{5} \mathrm{Si}_{3}$ phases. The Ni-Cr-Si-Al-Ta films deposited at $100 \mathrm{~W}$ and annealed at $300^{\circ} \mathrm{C}$ which exhibited the higher resistivity $2215 \mu \Omega$ $\mathrm{cm}$ with $-10 \mathrm{ppm} /{ }^{\circ} \mathrm{C}$ of temperature coefficient of resistance (TCR).
\end{abstract}

\section{Introduction}

Rapid technological advancements in many electronics industries, such as in the telecommunication and information, the aerospace, and the precision measurement sectors of industry, require the continuous development of electronic components to achieve higher precision, reliability, and integration [1]. Among these components, the resistor is one of the fundamental components and is primarily used in electronic circuits. In this respect, the demands for thin film resistors with low temperature coefficients of resistance (TCR) and high precision have been increasing dramatically in recent years [2-5].

The temperature coefficient of resistance (TCR) is an important technical parameter of thin film resistors. A high TCR will result in resistance value drifting and will consequently influence the accuracy of resistors as the temperature changes [6]. The main factors influencing the TCR include the sputtering process, annealing temperature, and film composition, whereas film composition plays a decisive role among these three factors. Therefore, employing an appropriate method for depositing a suitable film composition is the key to obtaining high-resistance resistors with a low TCR.

Extensive and rapid development in high entropy alloy has been conducted since the recent years by Yeh et al. [7]. These alloys are defined to have five or more principal metallic elements, with the concentration of each element varying between $5 \%$ and $35 \%$. It is generally found that high entropy alloys form simple solid solution structures (rather than many complex phases) at elevated temperatures because of large mixing entropies. The simple crystal structures possess many excellent properties [8], such as easy of nanoprecipitation, high hardness, and superior resistance to temper softening, wear, oxidation, and corrosion. The recent progress in HEAs, such as many new face-centered cubic (fcc) and body-centered cubic (bcc) HEAs and some high entropy bulk metallic glasses have been developed. They display an excellent mechanical response and good wear resistance at low and high temperatures, as well as good plastic behavior [9-12]. 
$\mathrm{Ni}-\mathrm{Cr}$ thin films are employed in integrated circuits, where low noise, good power dissipation, and a near-zero temperature coefficient of resistance are important requirements. Several studies have reported on the deposition of $\mathrm{Ni}-\mathrm{Cr}$ resistive films by thermal evaporation [13-16] and radio frequency $(\mathrm{RF})$ sputtering, primarily for use as hybrid resistors $[17,18]$. Extensive work has been reported on the control of the sheet resistance $R_{s}$ and TCR of Ni-Cr resistors by doping the films with different impurities. If silicon is added to the alloys, $\mathrm{Ni}-\mathrm{Cr}$-Si thin film resistors with very low temperature coefficients of resistivity are obtained, but the alloy resistivities are not significantly increased [1]. In our previous study, the effects of aluminum addition and annealing on the microstructure and electrical properties of Ni-Cr-Si films have been reported [19]. The electrical resistivities of the $\mathrm{Ni}-\mathrm{Cr}-\mathrm{Si}-\mathrm{Al}$ films were higher than those of the Ni-Cr-Si films annealed at temperatures below $400^{\circ} \mathrm{C}$, and the annealed Ni-Cr-Si-Al films exhibited a TCR close to zero. However, aluminum element has lower melting point $\left(660^{\circ} \mathrm{C}\right)$, which is not good for stability. The tantalum, with high melting point is at $3020^{\circ} \mathrm{C}$, will be being beneficial for thermal stability of resistive thin films [20].

To obtain resistive thin films with high resistivity and a low TCR, the concept of high entropy alloy was introduced to investigate the Ni-Cr-Si-Al-Ta composition as thin film resistors based on previously study of $\mathrm{Ni}-\mathrm{Cr}-\mathrm{Si}-\mathrm{Al}$ thin resistor [19]. The effects of sputtering power and annealing temperature on the phases and microstructural and electrical properties of $\mathrm{Ni}-\mathrm{Cr}-\mathrm{Si}-\mathrm{Al}-\mathrm{Ta}$ thin films were investigated.

\section{Experimental Procedure}

$\mathrm{Ni}-\mathrm{Cr}-\mathrm{Si}-\mathrm{Al}-\mathrm{Ta}$ thin films of $80 \mathrm{~nm}$ in thickness were deposited on the substrates using a DC magnetron cosputtering system having a sputtering rate of $5 \mathrm{~nm} / \mathrm{min}$. $\mathrm{Ni}_{0.35^{-}}$ $\mathrm{Cr}_{0.25}-\mathrm{Si}_{0.2}-\mathrm{Al}_{0.2}$ and tantalum of diameter $76.2 \mathrm{~mm}$ were used as targets. The sputtering chamber was evacuated to a background pressure of $7 \times 10^{-7}$ Torr by a cryopump, and then the sputtering gas Ar with a purity of $99.999 \%$ at flow of $60 \mathrm{sccm}$ was introduced into the chamber using mass flow controllers, by which the working pressure was $4.3 \times 10^{-3}$ Torr. Thin films deposited on glass plates at room temperature were subjected to electron probe microanalysis (EPMA) and X-ray diffraction (XRD) studies, while thin films on $\mathrm{Al}_{2} \mathrm{O}_{3}$ substrates (size: $25 \mathrm{~mm}^{2}$ ) were used for measuring the electrical properties. The DC power was adjusted at $100 \mathrm{~W}$ and $200 \mathrm{~W}$, respectively. The as-deposited films were annealed at 250 to $500^{\circ} \mathrm{C}$ for 4 hours, with a heating rate of $5^{\circ} \mathrm{C} / \mathrm{min}$ in air.

The sheet resistance $R_{s}$ of the films was measured using the four-point probe technique, and the thickness $t$ of the films was measured by FE-SEM (cross-section). The resistivity measured by the four-probe method was consistent with the resistivity obtained by the product of $R_{s}$ and $t$. The TCR values of the $\mathrm{Ni}-\mathrm{Cr}-\mathrm{Si}-\mathrm{Al}-\mathrm{Ta}$ films were measured on thin long strips cleaved from the substrate. Electrical contacts to the two ends of the resistive strips were obtained by selectively coating the ends with sputtered Ag. The DC resistance of the strips was measured on digit multimeter (HP 34401A) at different temperatures $\left(25^{\circ} \mathrm{C}\right.$ and $\left.125^{\circ} \mathrm{C}\right)$. TCR of the Ni-Cr$\mathrm{Si}-\mathrm{Al}-\mathrm{Ta}$ films was measured by the following relation:

$$
\mathrm{TCR}=\left[\left(\frac{\Delta R}{\Delta T}\right) \times \frac{1}{R}\right] \times 10^{6} \mathrm{ppm} / \mathrm{K} .
$$

The composition of the deposited films was determined by Auger electron spectroscopy (AES). AES depth profiles were obtained in a PHI 550ESCA/SAM Auger microprobe (Physical Electronics, USA). The crystallinity of the films was analyzed by X-ray diffraction (XRD, Bruker D8A Germany), using $\mathrm{Cu} \mathrm{K}_{\alpha}$ radiation for $2 \theta$ values from $20^{\circ}$ to $70^{\circ}$, with a scan speed of $3^{\circ} \mathrm{min}^{-1}$ and a grazing angle of $0.5^{\circ}$ at $40 \mathrm{kV}$ and $40 \mathrm{~mA}$. Microstructural and thickness observations of the cross-sectional and plane-view morphology of thin films grown on glass substrates were analyzed by field-emission scanning electron microscopy (FE-SEM, Hitachi S-4700 Japan) with an accelerating voltage of $20 \mathrm{kV}$. The microstructure of the films was also investigated by a field-emission transmission electron microscope (FE-TEM, FEIE.O. Tecnai F20) equipped with an energy-dispersive spectrometer at an acceleration voltage of $200 \mathrm{kV}$. TEM specimens were prepared by disk cutting, mechanical polishing, dimpling, and ion milling. A Fischione 150 ultrasonic disk cutter (Fischione Instruments Inc., Export, PA) was used to cut a $3 \mathrm{~mm}$ sample, which was then mechanically polished to approximately $100 \mu \mathrm{m}$ in thickness using a diamond lapping film. The sample thickness during lapping was accurately controlled by a tripod polisher (SPI Supplies, West Chester, PA). Next, the polished sample was dimpled to a thickness of approximately $4 \mu \mathrm{m}$ using a Fischione 150 dimpling grinder, followed by ion milling on both sides with a Fischione 1010 ion miller to achieve an electron transparent thickness $(<100 \mathrm{~nm})$.

\section{Results and Discussion}

3.1. The Compositions, Phase Transformation, and Microstructure of the Sputtered Films. Electron probe microanalysis (EPMA) was used to determine the film compositions. The relative concentrations of nickel, chromium, silicon, aluminum, and tantalum were measured at three points in the sputtered films, respectively. The average values are listed in Figure 1. The results indicate that the composition of the sputtered Ni-Cr-Si-Al-Ta films with different sputtering powers were $23.5 \% \mathrm{Ni}, 14.6 \% \mathrm{Cr}, 23.6 \% \mathrm{Si}, 16.8 \% \mathrm{Al}$, and $21.5 \% \mathrm{Ta}$ at $100 \mathrm{~W}$ and $24.5 \% \mathrm{Ni}, 13.8 \% \mathrm{Cr}, 23.6 \% \mathrm{Si}, 17.6 \%$ $\mathrm{Al}$, and $20.5 \% \mathrm{Ta}$ at $200 \mathrm{~W}$, respectively. It was found that the Ta content was about $20 \%$. However, these films are accorded to the rule of high entropy alloys which have five or more principal metallic elements with the concentration of each element varying between $5 \%$ and $35 \%$.

Figure 2 shows $\mathrm{X}$-ray diffraction patterns of $\mathrm{Ni}-\mathrm{Cr}-\mathrm{Si}$ $\mathrm{Al}-\mathrm{Ta}$ films at $200 \mathrm{~W}$, for the as-deposited samples and those annealed at various temperatures for $240 \mathrm{~min}$. All of the Ni-Cr-Si-Al-Ta films annealed at $\leq 400^{\circ} \mathrm{C}$ exhibited an amorphous structure, indicating that none of the elements crystallized or oxidized. The term amorphous is a general term that refers to a solid state with a nonperiodical atomic 


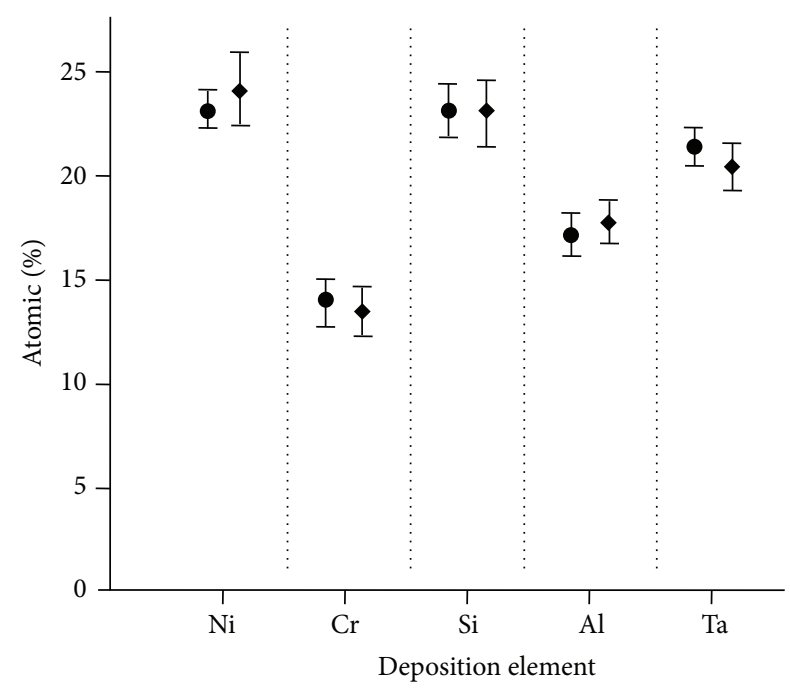

Figure 1: Compositions of Ni-Cr-Si-Al-Ta thin films with different DC sputtering powers sputtered on cooper sheet.

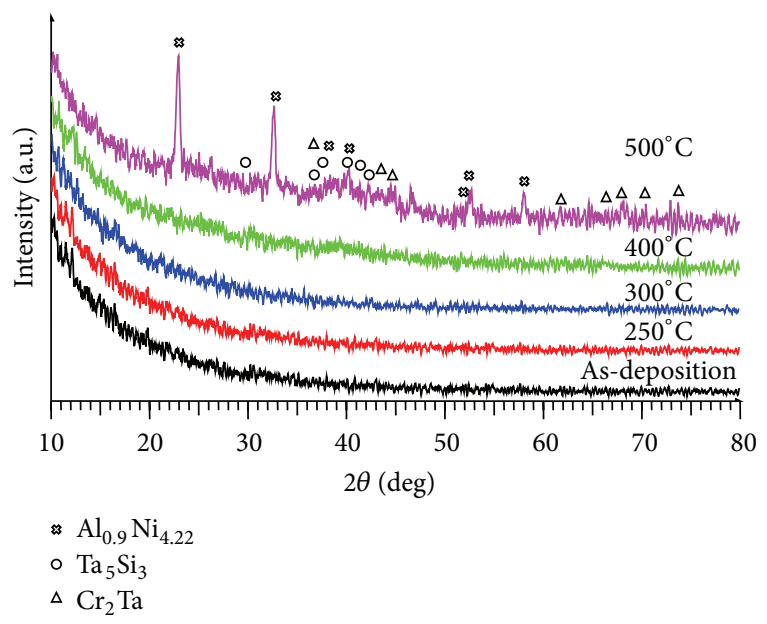

FIgURE 2: X-ray diffraction patterns of Ni-Cr-Si-Al-Ta thin films sputtered at $200 \mathrm{~W}$ with different annealing temperatures.

arrangement. A particular feature of an amorphous material at the atomic level in comparison with crystalline material is the absence of long-range order in the atoms. However, the atomic arrangement at the atomic scale (distance of a few diameters of atoms) is periodical [21]. The structure of crystalline materials can be easily determined by describing the unit cells of the crystals. The characterization of an amorphous structure is much more difficult due to the broadening of diffraction patterns and the lack of reflections during X-ray investigations. Further study is needed to use transmission electron microscopy for crystalline analysis. It is interesting to point out that the Ni-Cr-Si-Al-Ta films did not oxidize after $500^{\circ} \mathrm{C}$ annealing in air; there are only alloy phases formed in the Ni-Cr-Si-Al-Ta films. Yeh et al. [7, 22] reported that the HEAs can enhance the high temperature strength, corrosion, oxidation resistance, and so on.
Figure 3 shows X-ray diffraction patterns of Ni-Cr-Si-AlTa films with different sputtering powers on glass substrates, for as-deposited samples and those annealed at $500^{\circ} \mathrm{C}$ for $240 \mathrm{~min}$. The figure shows that the as-deposited films had an amorphous structure. When the annealing temperature was set to $500^{\circ} \mathrm{C}$, the crystallization of $\mathrm{Al}_{0.9} \mathrm{Ni}_{4.22}, \mathrm{Ta}_{5} \mathrm{Si}_{3}$, and $\mathrm{Cr}_{2}$ Ta was clearly discernible. In Figure 3(b), which also shows the results at different sputtering power, the intensity of XRD peaks clearly increases with increasing sputtering power up to $200 \mathrm{~W}$. It indicates that the crystalline film is strongly influenced by the sputtering power when the films annealed at high temperature. This may be attributed to the fact that, at high sputtering power, the ejected metal atoms possess higher kinetic energy when they arrive on the substrate [23]. Consequently, these $\mathrm{Ni}, \mathrm{Cr}, \mathrm{Si}, \mathrm{Al}$, and $\mathrm{Ta}$ atoms have sufficient kinetic energy to rearrange themselves to form closer packing layer, resulting in a highly nanocrystalline film structure. The numbers or energy of electrons and ions in glow discharge plasma will increase with an increment in sputtering powers, in the case of using metal target $[24,25]$. That is, the energy of sputtered atom which is obtained from the positive ions colliding to target will increase with increasing sputtering power. It is also possible that the highly energized electrons with increasing sputtering power will bombard the surface of growing film at the substrate, providing in the form thermal energy. This energy might act as an additional energy to promote the growth of crystalline. Therefore, it can be concluded that as the sputtering power increases, the number and the momentum of the sputtering particles will also increase. The atoms become more mobile on the surface of the film as the result of the higher bombardment rates on them [26].

Figure 4 shows SEM micrographs of the Ni-Cr-Si-Al-Ta thin films with different sputtering powers and annealing temperatures. Some heterogeneous phases appeared after annealing at $400^{\circ} \mathrm{C}$ in the Ni-Cr-Si-Al-Ta thin films deposited at $200 \mathrm{~W}$, as shown in Figure 4(b), and it obviously appeared after annealing at $500^{\circ} \mathrm{C}$ as shown in Figure 4(c), which is consistent with the XRD analysis (Figure 2). These crystal phases should belong to $\mathrm{Al}_{0.9} \mathrm{Ni}_{4.22}, \mathrm{Ta}_{5} \mathrm{Si}_{3}$, and $\mathrm{Cr}_{2} \mathrm{Ta}$. For the $\mathrm{Ni}-\mathrm{Cr}-\mathrm{Si}$-Al-Ta thin films deposited at $100 \mathrm{~W}$ and annealed at $500^{\circ} \mathrm{C}$, the heterogeneous phases were also observed, as shown in Figure 4(d).

Figure 5 shows a typical TEM bright field image and selected-area electron diffraction (SAED) patterns of the $\mathrm{Ni}-\mathrm{Cr}$-Si-Al-Ta thin films with different sputtering powers and annealing temperatures. For Ni-Cr-Si-Al-Ta thin films deposited at $200 \mathrm{~W}$ and annealed at $300^{\circ} \mathrm{C}$, it shows that the film with nanocrystalline structure appeared as shown in Figure 5(a). This result can be confirmed using the SAED patterns as shown in Figure 5(b). Therefore, the increase of sputtering power obviously causes the formation of a crystalline phase. With the annealing temperature increasing, more nanocrystallites were observed significantly to nucleate homogeneously throughout thin films and the SAED patterns changed to Debye-Scherrer-type rings (Figures 5(c) and $5(\mathrm{~d}))$. However, the crystallites of the films annealed at $500^{\circ} \mathrm{C}$ were obviously larger than the films annealed at $300^{\circ} \mathrm{C}$. The phase analysis performed from the electron 

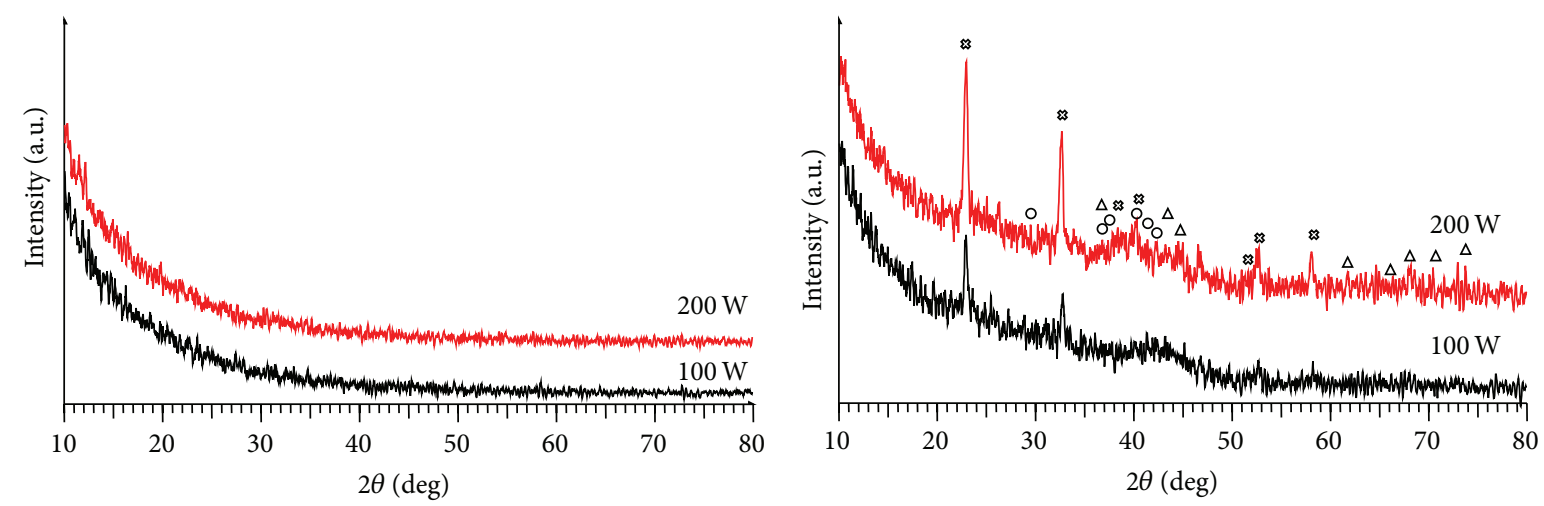

$$
\begin{aligned}
& \text { - } \mathrm{Ta}_{5} \mathrm{Si}_{3} \\
& \triangle \mathrm{Cr}_{2} \mathrm{Ta} \\
& \approx \mathrm{Al}_{0.9} \mathrm{Ni}_{4.22}
\end{aligned}
$$

(a)

(b)

FIGURE 3: X-ray diffraction patterns of Ni-Cr-Si-Al-Ta thin films with different sputtering powers: (a) as-deposited and annealed at (b) $500^{\circ} \mathrm{C}$.

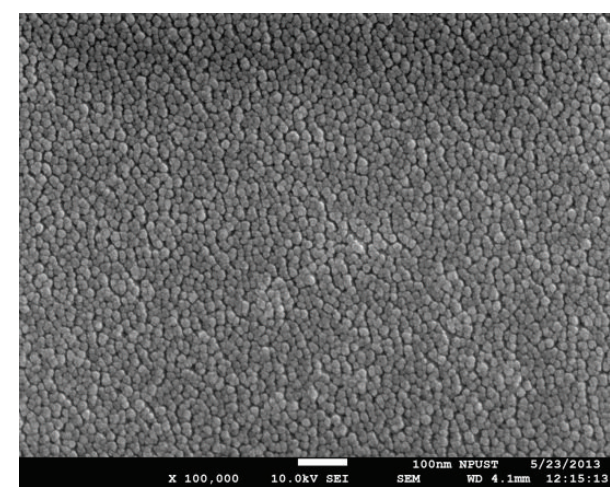

(a)

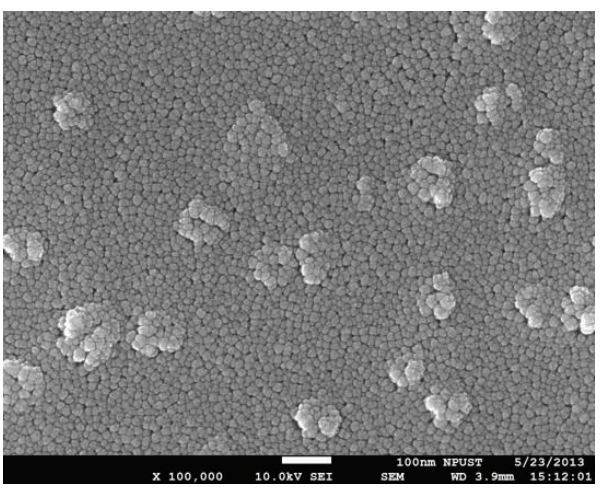

(c)

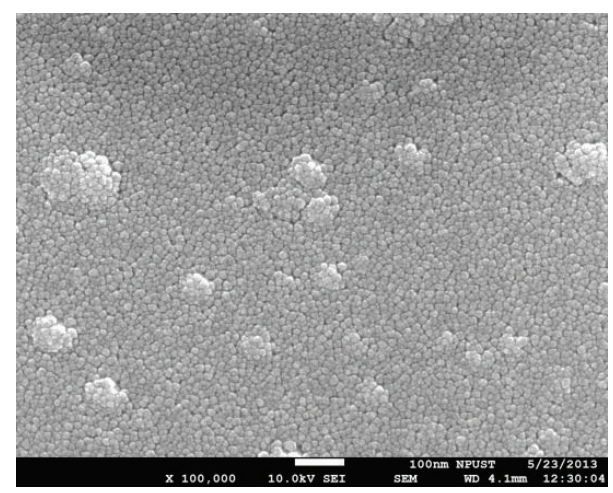

(b)

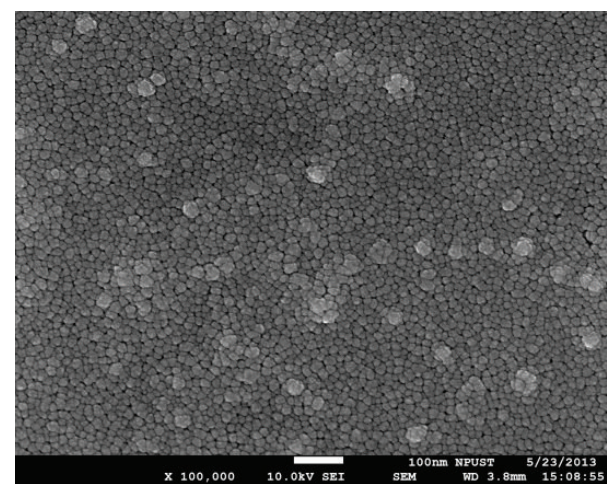

(d)

FIGURE 4: SEM micrographs of Ni-Cr-Si-Al-Ta films sputtered and annealed at (a) $200 \mathrm{~W} / 300^{\circ} \mathrm{C}$, (b) $200 \mathrm{~W} / 400^{\circ} \mathrm{C}$, (c) $200 \mathrm{~W} / 500^{\circ} \mathrm{C}$, and (d) $100 \mathrm{~W} / 500^{\circ} \mathrm{C}$.

diffraction patterns enables the identification of $\mathrm{Al}_{0.9} \mathrm{Ni}_{4.22}$ and $\mathrm{Cr}_{2}$ Ta phases. The increase in peak intensities indicates an enhancement in the crystallinity of films because it is generally noted that the crystallinity can be enhanced while increasing the annealing temperature $[27,28]$.
It is still of interest when considering phase competition between the solid solution phases and potential compounds (intermetallics). In other words, it is important to understand the thermodynamic nature of the phase stability of the solid solutions in $\mathrm{Ni}-\mathrm{Cr}-\mathrm{Si}-\mathrm{Al}-\mathrm{Ta}$ thin films at elevated 


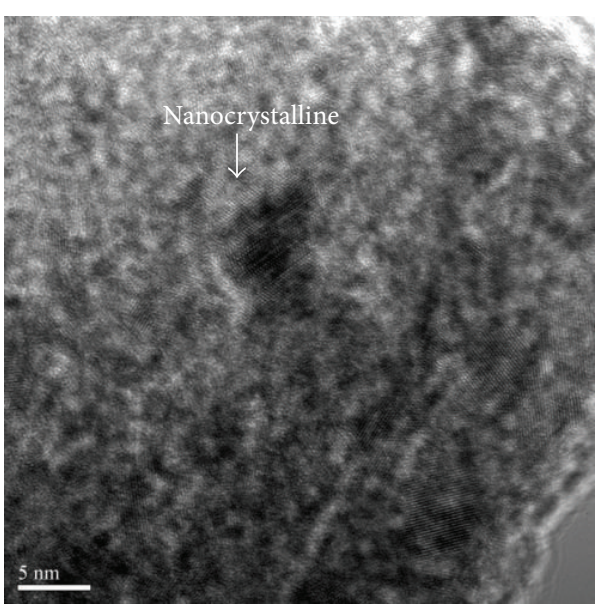

(a)

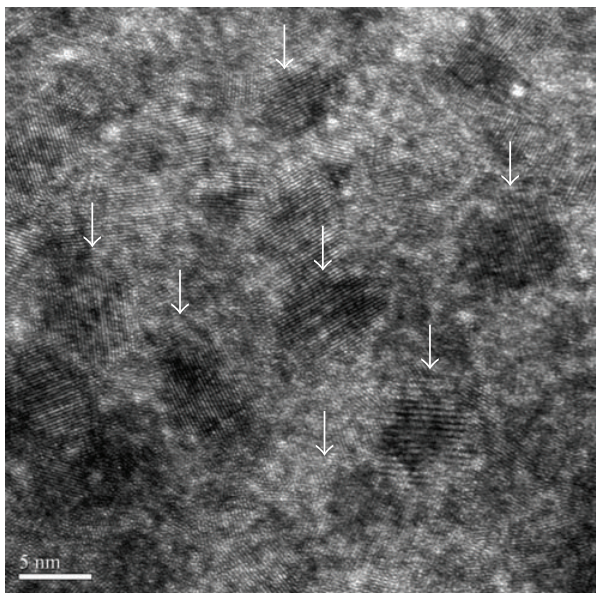

(c)

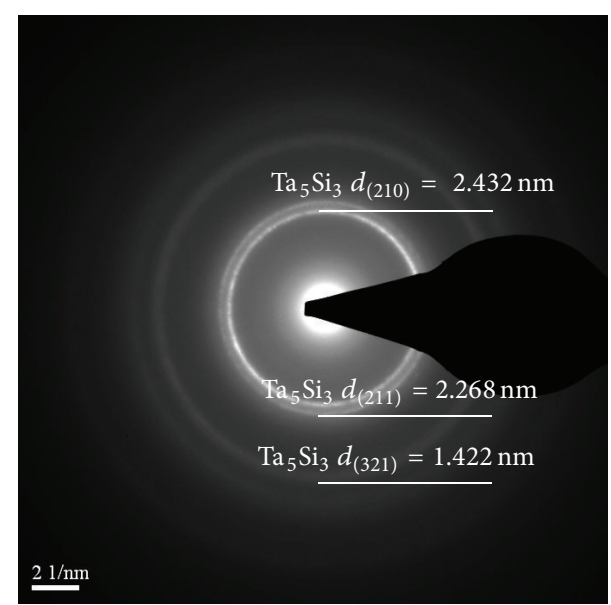

(b)

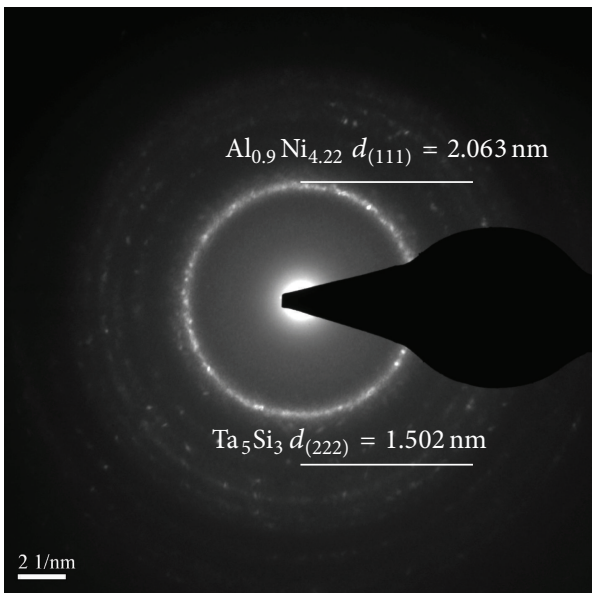

(d)

FIGURE 5: TEM micrographs and selected-area electron diffraction of Ni-Cr-Si-Al-Ta films sputtered and annealed at $200 \mathrm{~W} / 300^{\circ} \mathrm{C}$ for (a) and (b) and $200 \mathrm{~W} / 500^{\circ} \mathrm{C}$ for (c) and (d).

temperatures. Solid solutions are stable when the mixed crystal has lower free energy than the alternative-building up two crystals of different composition or building up a new structure in which the foreign atoms are put on ordered sites. The free energy is given by the following relation:

$$
G=E+P V-T S,
$$

where $E$ is largely determined by the structural energy and the entropy is a measure of the randomness of the structure. If an atom added at random greatly increases the structure energy, the solid solution is unstable and two crystal structures form. On the other hand, if the addition of a foreign atom greatly lowers the structure energy, the system tends to form an ordered new phase. If the energy is not much changed, the entropy is increased by random additions so that the solid solution has the lowest energy and is the stable configuration [29].

3.2. The Electrical Properties of Ni-Cr-Si-Al-Ta Thin Films. To apply a material in thin film resistors, it is important to know (i) the range of resistivity in which a near-zero TCR can be obtained and (ii) the detailed resistance behavior in the range of working temperatures (usually $-55^{\circ} \mathrm{C}$ to $125^{\circ} \mathrm{C}$ ) [30]. Figure 6 shows the effect of annealing temperature and sputtering power on the electrical properties of the $\mathrm{Ni}-\mathrm{Cr}$-Si-Al-Ta films. The resistivity of Ni-Cr-Si-Al-Ta films decreases obviously with increasing of annealing temperatures. This result indicates that atomic configuration changes have occurred in Ni-Cr-Si-Al-Ta films. It is interesting to point that the resistivities of the Ni-Cr-Si-Al-Ta films are different between 100 and $200 \mathrm{~W}$ of sputtering power at $300^{\circ} \mathrm{C}$ annealing. The resistivity of Ni-Cr-Si-Al-Ta films is $\sim 2200$ and $\sim 1600 \mu \Omega-\mathrm{cm}$ for $100 \mathrm{~W}$ and $200 \mathrm{~W}$, respectively. There is more than $35 \%$ difference in resistivity between them. The reason for this is due to different crystal structures of $\mathrm{Ni}-\mathrm{Cr}$ $\mathrm{Si}$-Al-Ta films with different sputtering power at $300^{\circ} \mathrm{C}$; one is an amorphous at $100 \mathrm{~W}$ and the other one is nanocrystalline at $200 \mathrm{~W}$. It is also interesting to note that the resistivity of the Ni-Cr-Si-Al-Ta films decreases with increasing the annealing temperature. From the above XRD and TEM results, the crystallinity of $\mathrm{Ni}-\mathrm{Cr}$-Si-Al-Ta films was enhanced 


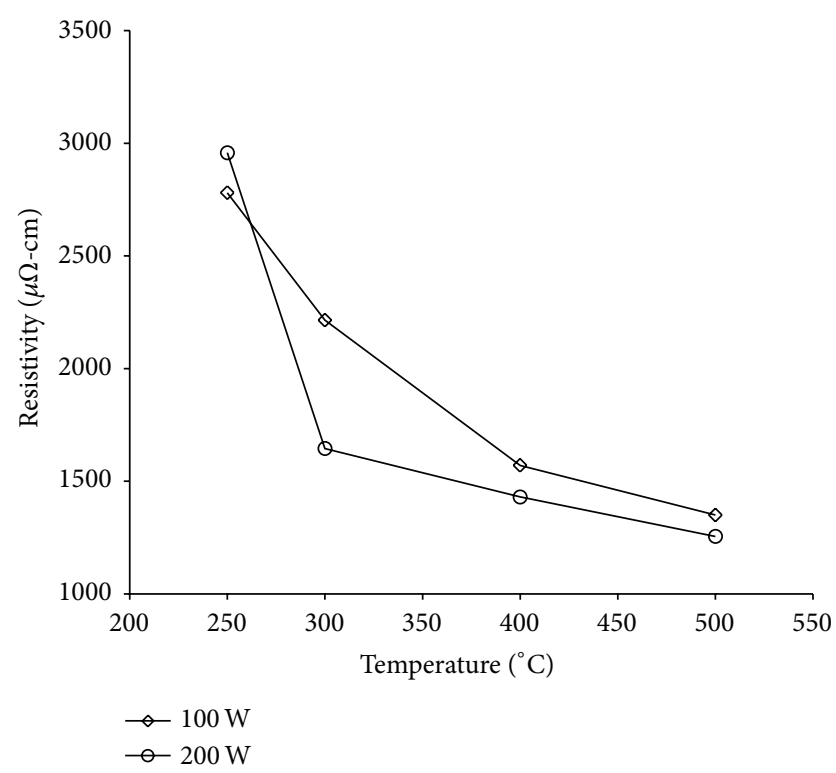

FIGURE 6: Room temperature resistivity of Ni-Cr-Si-Al-Ta films with different sputtering powers and annealing temperatures.

with increasing the annealing temperature. In general, by increasing the annealing temperature, the resistivity of $\mathrm{Ni}$ $\mathrm{Cr}$-Si-Al-Ta films increases since the grain boundaries, crystal defects, and oxides generation of the film were increased [6]. In this investigation, the resistivity was decreased which can be attributed to an increase in alloy phases $\left(\mathrm{Al}_{0.9} \mathrm{Ni}_{4.22}, \mathrm{Ta}_{5} \mathrm{Si}_{3}\right.$ and $\mathrm{Cr}_{2} \mathrm{Ta}$ ) with increasing the annealing temperature, as shown in Figures 2 and 5. According to Matthiessen's rule, the resistivity of a continuous film is a cumulative effect of various electron scattering processes in the film. The resistivity $\rho_{T}$ of the film is given by the following relation:

$$
\rho_{T}=\rho_{B}+\rho_{S}+\rho_{I}
$$

where $\rho_{B}, \rho_{S}$, and $\rho_{I}$ are contributions made to the total resistivity of the film due to scattering at ideal lattice (same as bulk), scattering at film surface (dependent on film thickness), and scattering at imperfections (grain boundaries and impurities), respectively.

Figure 7 shows the effect of annealing temperature and sputtering power on the temperature coefficient of resistivity (TCR) of the Ni-Cr-Si-Al-Ta films. The TCR values were increased with increasing of annealing temperature. TCR values were about $200 \mathrm{ppm} /{ }^{\circ} \mathrm{C}$ annealed below $300^{\circ} \mathrm{C}$ at 200 W. Moreover, the Ni-Cr-Si-Al-Ta films deposited at $100 \mathrm{~W}$ annealed at $300^{\circ} \mathrm{C}$ exhibit a TCR close to zero because the films retain an amorphous structure after annealing. However, the TCR values of the films annealed at $500^{\circ} \mathrm{C}$ are about $1000 \mathrm{ppm} /{ }^{\circ} \mathrm{C}$. The TCR value becomes worse when the annealing temperature is increased. It can be explained that the annealing response of the TCR is the result of competition between a negative contribution from weak localization effects in the amorphous region and a positive contribution from crystalline phase grains [31]. For practical

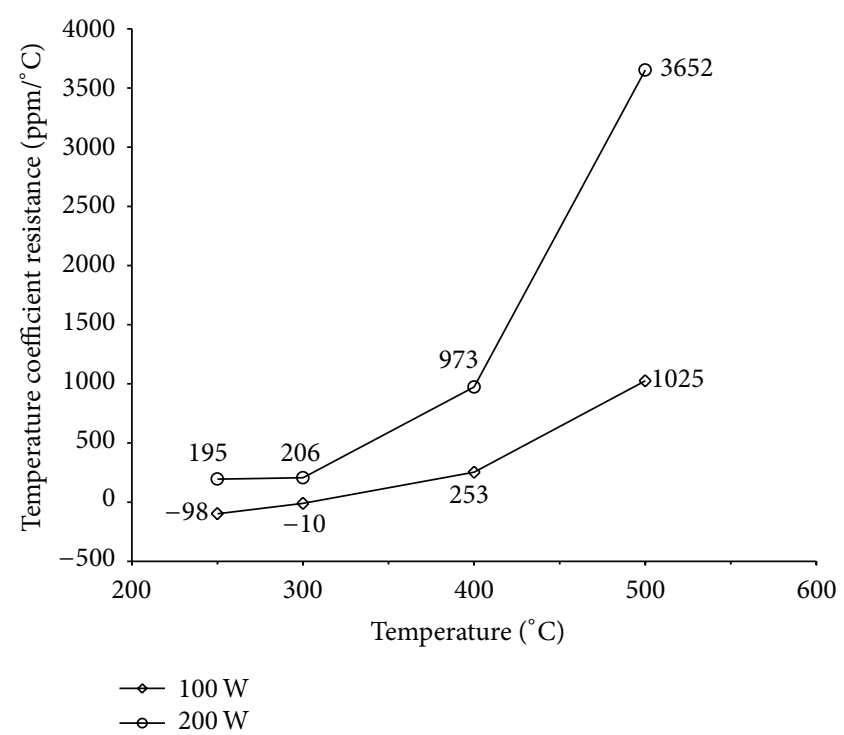

FIGURE 7: Temperature dependence of the TCR of Ni-Cr-Si-Al-Ta films with different sputtering powers and annealing temperatures.

purposes, it is important for films with a small TCR to possess high resistivity.

\section{Conclusion}

Ni-Cr-Si-Al (30/20/20/30 at.\%) alloy and Ta targets were deposited on the glass and $\mathrm{Al}_{2} \mathrm{O}_{3}$ substrates as thin film resistor materials by cosputtering method. The compositions of film are accorded to the rule of high entropy alloys which have five elements with the concentration of each element varying between 5\% and 35\%. There is an amorphous structure observed in the films with sputtering power $100 \mathrm{~W}$ at $300^{\circ} \mathrm{C}$. However, the annealing temperature was at $500^{\circ} \mathrm{C}$; both films $(100 \mathrm{~W}$ and $200 \mathrm{~W})$ crystallized into $\mathrm{Al}_{0.9} \mathrm{Ni}_{4.22}, \mathrm{Cr}_{2} \mathrm{Ta}$, and $\mathrm{Ta}_{5} \mathrm{Si}_{3}$ phases. Electrical properties indicated that the Ni-CrSi-Al-Ta films with $100 \mathrm{~W}$ exhibited the smallest temperature coefficient of resistance $\left(-10 \mathrm{ppm} /{ }^{\circ} \mathrm{C}\right)$ with higher resistivity $\sim 2200 \mu \Omega-\mathrm{cm}$ after annealing at $300^{\circ} \mathrm{C}$ in air. For practical purposes, it is important for films with a small TCR to possess high resistivity. In this study, the introduction of HEAs concept can effectively enhance the electrical properties of $\mathrm{Ni}-\mathrm{Cr}$ based thin films, satisfying the requirements for thin film resistor application.

\section{Conflict of Interests}

The authors declare that there is no conflict of interests regarding the publication of this paper.

\section{Acknowledgment}

The authors would like to acknowledge financial support of this research from the Ministry of Science and Technology of Taiwan under Contract no. 102-2221-E-020-008-MY3. 


\section{References}

[1] B.-J. Lee, D.-C. Lee, and C.-S. Kim, "Electrical properties of sputtered Ni-Cr-Al-Cu thin film resistors with $\mathrm{Ni}$ and $\mathrm{Cr}$ contents," Journal of the Korean Physical Society, vol. 40, no. 2, pp. 339-343, 2002.

[2] A. P. Bhatt, C. A. Luck, and D. M. Stevenson, in Proceedings of the International Symposium on Microelectronics, p. 370, 1984.

[3] K. Matsuda, K. Sato, T. Doi, K. Ogata, and K. Konishi, "Super precision metal film resistors," National Technical Report, vol. 26, pp. 283-288, 1980.

[4] W. E. Isler and L. A. Kitchman, "Influence of deposition and processing parameters on the tcr of ni-cr-cu-al alloy film resistors," IEEE Transactions on Parts, Materials and Packaging, vol. 5, no. 3, pp. 139-146, 1969.

[5] E. Schippel, "Modifications test of vacuum deposition $\mathrm{Ni} / \mathrm{Cr}$ films with Mn and Si for thin film resistors," Kristall und Technik, vol. 15, no. 8, pp. 917-919, 1980.

[6] X. Y. Wang, Z. S. Zhang, and T. Bai, "Investigation on powder metallurgy $\mathrm{Cr}-\mathrm{Si}-\mathrm{Ta}-\mathrm{Al}$ alloy target for high-resistance thin film resistors with low temperature coefficient of resistance," Materials and Design, vol. 31, no. 3, pp. 1302-1307, 2010.

[7] J. W. Yeh, S. K. Chen, S. J. Lin et al., "Nanostructured highentropy alloys with multiple principal elements: novel alloy design concepts and outcomes," Advanced Engineering Materials, vol. 6, no. 5, pp. 299-274, 2004.

[8] J.-W. Yeh, S.-K. Chen, J.-Y. Gan et al., "Formation of simple crystal structures in $\mathrm{Cu}-\mathrm{Co}-\mathrm{Ni}-\mathrm{Cr}-\mathrm{Al}-\mathrm{Fe}-\mathrm{Ti}-\mathrm{V}$ alloys with multiprincipal metallic elements," Metallurgical and Materials Transactions A: Physical Metallurgy and Materials Science, vol. 35, no. 8, pp. 2533-2536, 2004.

[9] C. Y. Hsu, J. W. Yeh, S. K. Chen, and T. T. Shun, "Wear resistance and high-temperature compression strength of Fcc $\mathrm{CuCoNiCrAl}_{0.5} \mathrm{Fe}$ alloy with boron addition," Metallurgical and Materials Transactions A, vol. 35, no. 5, pp. 1465-1469, 2004.

[10] O. N. Senkov, G. B. Wilks, J. M. Scott, and D. B. Miracle, "Mechanical properties of $\mathrm{Nb}_{25} \mathrm{Mo}_{25} \mathrm{Ta}_{25} \mathrm{~W}_{25}$ and $\mathrm{V}_{20} \mathrm{Nb}_{20} \mathrm{Mo}_{20} \mathrm{Ta}_{20} \mathrm{~W}_{20}$ refractory high entropy alloys," Intermetallics, vol. 19, no. 5, pp. 698-706, 2011.

[11] O. N. Senkov, S. V. Senkova, D. B. Miracle, and C. Woodward, "Mechanical properties of low-density, refractory multiprincipal element alloys of the Cr-Nb-Ti-V-Zr system," Materials Science and Engineering A, vol. 565, pp. 51-62, 2013.

[12] F. Otto, A. Dlouhý, C. Somsen, H. Bei, G. Eggeler, and E. P. George, "The influences of temperature and microstructure on the tensile properties of a CoCrFeMnNi high-entropy alloy," Acta Materialia, vol. 61, no. 15, pp. 5743-5755, 2013.

[13] D. S. Campbell and B. Hendry, "The effect of composition on the temperature coefficient of resistance of NiCr films," The British Journal of Applied Physics, vol. 16, no. 11, pp. 1719-1722, 1965.

[14] J. G. Swanson, D. S. Campbell, and J. C. Anderson, "A study of electrical conduction in island structure nickel and 80:20 nickel-chromium films," Thin Solid Films, vol. 1, no. 5, pp. 325342, 1968.

[15] L. Lassak and K. Hieber, "Structural and electrical properties of evaporated Cr-Ni films as a function of gas pressure," Thin Solid Films, vol. 17, no. 1, pp. 105-111, 1973.

[16] G. Nocerino and K. E. Singer, "The electrical and compositional structure of thin Ni-Cr films," Thin Solid Films, vol. 57, no. 2, pp. 343-348, 1979.
[17] M. I. Bîrjega, C. A. Constantin, I. T. Florescu, and C. Sârbu, "Crystallization of amorphous sputtered $55 \% \mathrm{Cr}-45 \% \mathrm{Ni}$ thin films," Thin Solid Films, vol. 92, no. 4, pp. 315-322, 1982.

[18] S. Schiller, U. Heisig, K. Goedicke et al., "Plasmatron sputtering for the production of high stability NiCr resistive films," Thin Solid Films, vol. 119, no. 2, pp. 211-216, 1984.

[19] D.-J. Feng, Y.-C. Lee, and Y.-B. Chen, "A Study of Ni-Cr-Sibased thin film resistors prepared by DC magnetron sputtering," International Journal of Materials Engineering and Technology, vol. 11, no. 2, pp. 149-164, 2014.

[20] S. Taioli, C. Cazorla, M. J. Gillan, and D. Alfè, "Melting curve of tantalum from first principles," Physical Review B, vol. 75, no. 21, Article ID 214103, 2007.

[21] C. Ng, S. Guo, J. Luan, S. Shi, and C. T. Liu, "Entropydriven phase stability and slow diffusion kinetics in an $\mathrm{Al}_{0.5} \mathrm{CoCrCuFeNi}$ high entropy alloy," Intermetallics, vol. 31, pp. 165-172, 2012.

[22] M.-H. Tsai and J.-W. Yeh, "High-entropy alloys: a critical review," Materials Research Letters, vol. 2, no. 3, pp. 107-123, 2014.

[23] A. Anders, J. Andersson, and A. Ehiasarian, "High power impulse magnetron sputtering: current-voltage-time characteristics indicate the onset of sustained self-sputtering," Journal of Applied Physics, vol. 102, no. 11, Article ID 113303, 11 pages, 2007.

[24] D.-J. Kwak, M.-W. Park, and Y.-M. Sung, "Discharge power dependence of structural and electrical properties of Al-doped $\mathrm{ZnO}$ conducting film by magnetron sputtering (for PDP)," Vacuum, vol. 83, no. 1, pp. 113-118, 2008.

[25] N. Witit-Anun, J. Kaewkhao, and S. Chaiyakun, "Effect of sputtering power on structural and optical properties of ALN thin film deposited by reactive DC sputtering technique," Advanced Materials Research, vol. 770, pp. 177-180, 2013.

[26] A. Chaoumead, Y.-M. Sung, and D.-J. Kwak, "The effects of RF sputtering power and gas pressure on structural and electrical properties of ITiO thin film," Advances in Condensed Matter Physics, vol. 2012, Article ID 651587, 7 pages, 2012.

[27] M.-C. Jun and J.-H. Koh, "Effects of annealing temperature on properties of Al-doped $\mathrm{ZnO}$ thin films prepared by sol-gel dipcoating," Journal of Electrical Engineering and Technology, vol. 8, no. 1, pp. 163-167, 2013.

[28] Z. Z. Zhi, Y. C. Liu, B. S. Li et al., "Effects of thermal annealing on $\mathrm{ZnO}$ films grown by plasma enhanced chemical vapour deposition from $\mathrm{Zn}\left(\mathrm{C}_{2} \mathrm{H}_{5}\right)_{2}$ and $\mathrm{CO}_{2}$ gas mixtures," Journal of Physics D: Applied Physics, vol. 36, no. 6, pp. 719-722, 2003.

[29] X. Dong, J. Wu, and L. Mao, "The crystallization of Cr-Si-Ni-Al amorphous films-nucleation and growth of intermetallic phase $\mathrm{Cr}(\mathrm{Al}, \mathrm{Si})_{2}$," Intermetallics, vol. 11, no. 8, pp. 779-785, 2003.

[30] J. Roelke, "Nichrome thin film technology and its application," Electrocomponent Science and Technology, vol. 9, no. 1, pp. 51-57, 1980.

[31] S. Vinayak, H. P. Vyas, and V. D. Vankar, "Microstructure and electrical characteristics of Ni-Cr thin films," Thin Solid Films, vol. 515, no. 18, pp. 7109-7116, 2007. 

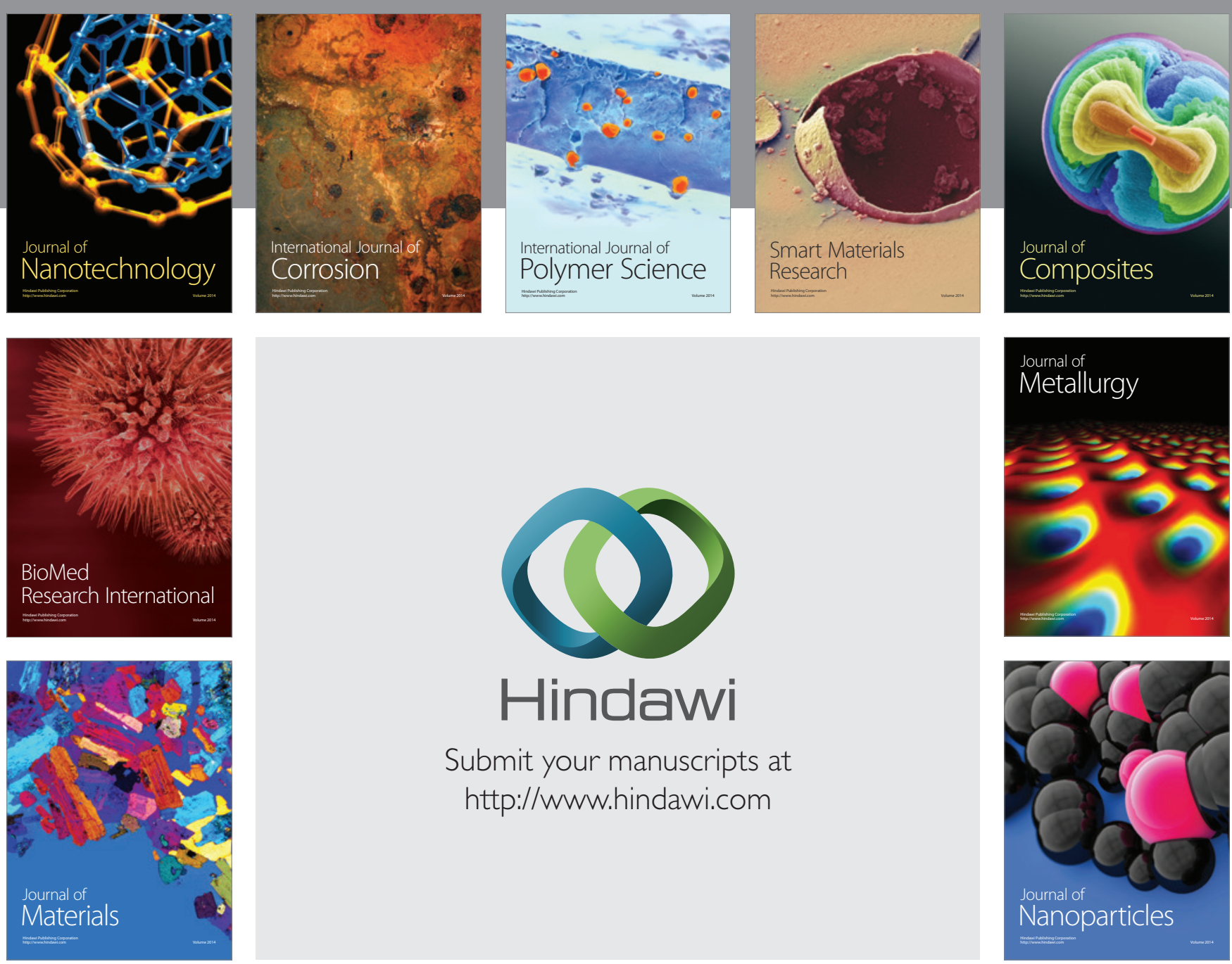

Submit your manuscripts at http://www.hindawi.com
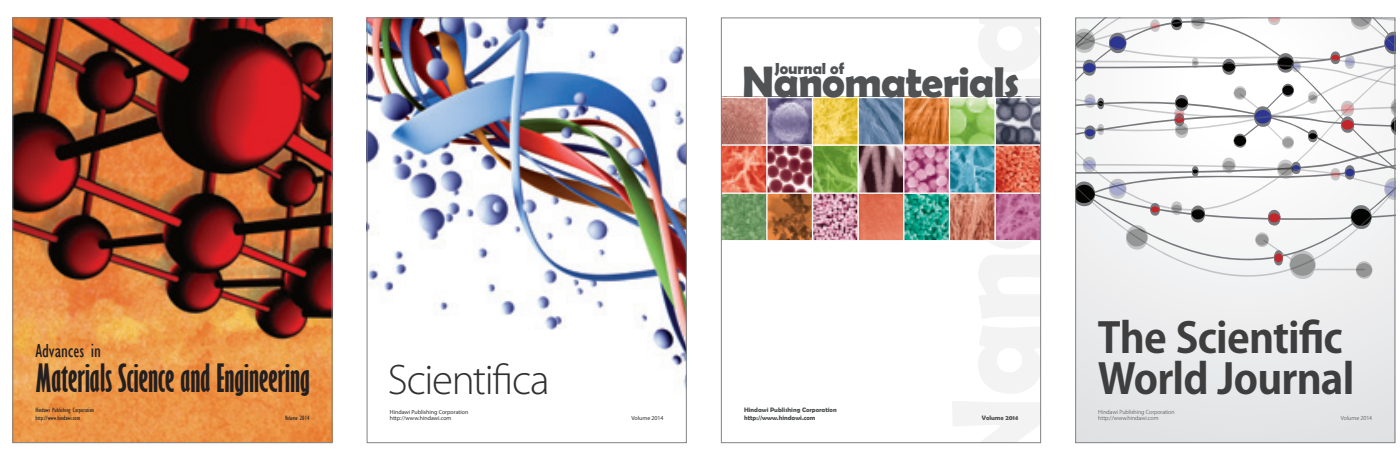

\section{The Scientific World Journal}
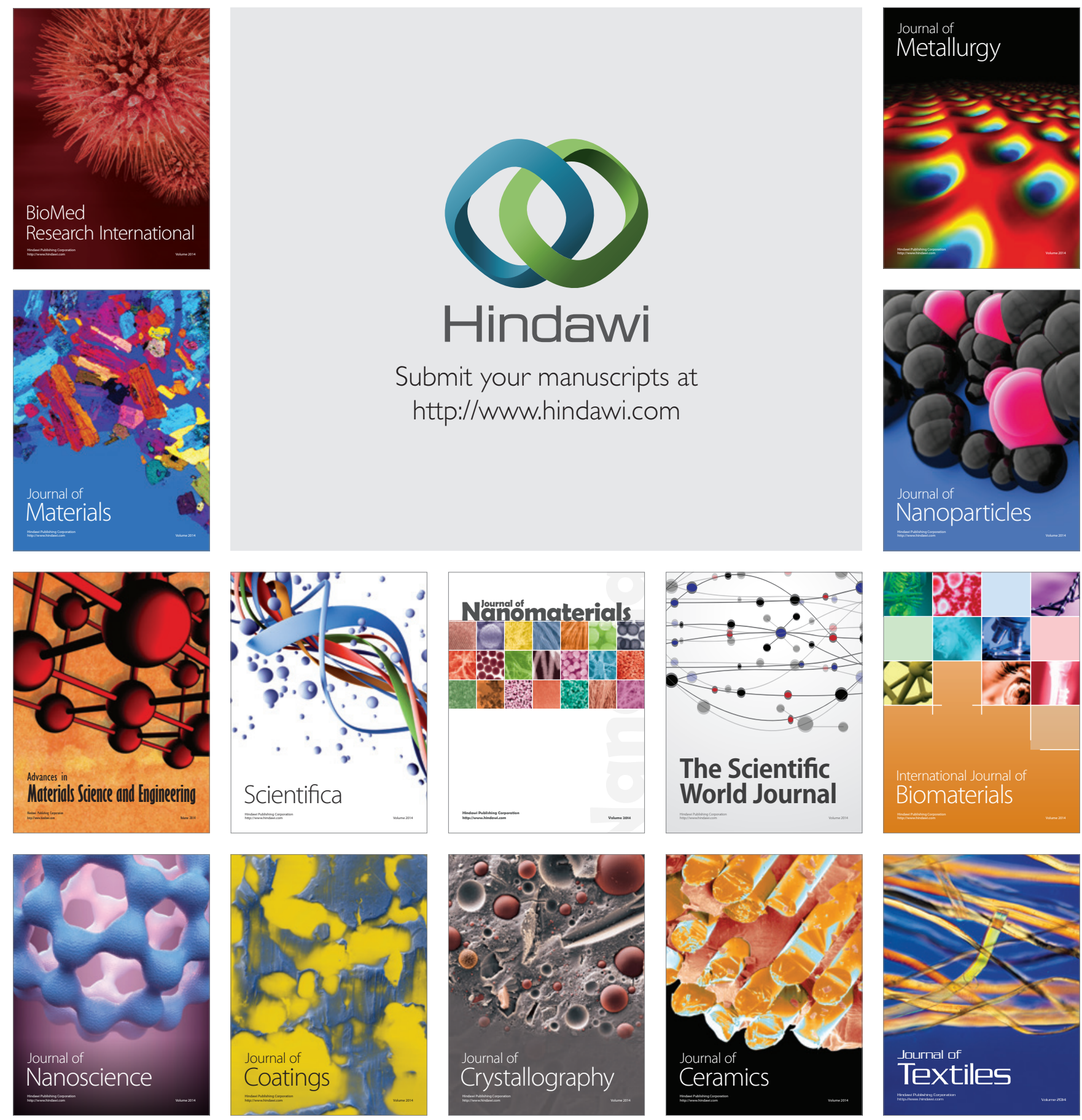